\title{
Systematic assessment and characterization of chronic pain in multiple sclerosis patients
}

\author{
Diana Ferraro ${ }^{1}$ - Domenico Plantone ${ }^{2}$ (D) . Franca Morselli ${ }^{1}$ - Giulia Dallari ${ }^{3} \cdot$ Anna M. Simone ${ }^{1} \cdot$ Francesca Vitetta $^{1}$. \\ Patrizia Sola ${ }^{1}$ - Guido Primiano ${ }^{4}$. Viviana Nociti ${ }^{4,5} \cdot$ Matteo Pardini $^{6,7} \cdot$ Massimiliano Mirabella $^{4}$. Catello Vollono ${ }^{4}$
}

Received: 26 September 2017 / Accepted: 5 December 2017

(C) Springer-Verlag Italia S.r.l., part of Springer Nature 2017

\begin{abstract}
Pain is one of the most disabling clinical symptoms in patients with multiple sclerosis (MS). Several studies have already assessed the prevalence of pain in MS patients, reporting variable results, probably due to methodological differences. The aim of this single-centre cross-sectional study was to define the prevalence and characteristics of chronic pain in a population of MS patients using validated tools, and to analyse these data in relation to demographic and clinical features, including disease duration and disability (EDSS and its single functional system scores). Of 397 enrolled patients, 23 were excluded due to a Beck's Depression Inventory Score $>19$. In the remaining 374 patients, the overall prevalence of chronic pain was $52.1 \%$, most frequently affecting the lower limbs (36.9\%). Neuropathic pain was the most frequent type of chronic pain (89 patients, overall prevalence of 23.7\%) and was associated with a sensory functional system involvement. Pain intensity was significantly higher in patients with neuropathic pain as opposed to patients with non-neuropathic pain. Patients with chronic pain and, in particular, patients with neuropathic pain had significantly higher EDSS scores than those without pain. Only $24 \%$ of patients with chronic pain and $33 \%$ of patients with neuropathic pain were on a specific long-lasting treatment for pain. The present study supports the routine assessment of neuropathic pain in MS patients, especially in those with a sensory functional system involvement, in order to avoid underdiagnosing and undertreating a potentially disabling condition.
\end{abstract}

Keywords Pain $\cdot$ Multiple sclerosis $\cdot$ Neuropathic symptoms $\cdot$ Pain treatment

\section{Introduction}

Pain is one of the most disabling clinical symptoms in patients with multiple sclerosis (MS) [1-6]. Many studies have assessed the prevalence of pain in MS patients, reporting a wide variability, ranging from $29 \%$ [1] to $92 \%$ [7], whereas a meta-analysis reported a prevalence of $63 \%$ [8]. When comparing studies evaluating pain in

Domenico Plantone

domenicoplantone@hotmail.com

1 Neurology Unit, Department of Biomedical Metabolic and Neurosciences, University of Modena and Reggio Emilia, Modena, Italy

2 S.O.C. Neurologia, Ospedale San Biagio, Piazza Vittime dei Lager Nazifascisti n.1, 28845 Domodossola, VB, Italy

3 Psychology Unit, Nuovo Ospedale Civile S. Agostino Estense, Modena, Italy
MS, methodological differences and non-uniformity of the studied populations are evident, making this symptom somewhat unclear and often underdiagnosed [8,9]. Pain is classified as nociceptive or neuropathic [10], on the basis of the pathophysiology. The first arises from chemical, thermal and mechanical stimulation of A-delta and C fibers [11]. It is usually a sharp pain, well localized and selflimiting, and generally resolves with the restoration of

4 Neurology Institute, Università Cattolica del Sacro Cuore, Fondazione Policlinico Universitario Agostino Gemelli, Rome, Italy

5 Fondazione Don C Gnocchi Onlus, Milan, Italy

6 Department of Neuroscience, Rehabilitation, Ophthalmology, Genetics, Maternal and Child Health, University of Genoa, Genova, Italy

7 IRCCS IST S. Martino Hospital, Genoa, Italy 
tissue integrity. The second arises as a direct consequence of a lesion or disease affecting the somatosensory system [12]. On the other hand, the duration of pain symptoms permits to distinguish between acute and chronic pain. Acute pain is a short-term pain that warns of tissue damage and has a protective function. Chronic pain is long-lasting [13] and has been defined as a constant or intermittent pain which persists for more than 3 months after the resolution of any tissue damage, albeit the minimum duration needed to define chronic or persistent pain is still very debated [13, 14]. Persistent pain syndromes offer no biological advantage and cause suffering, distress and deterioration of quality of life (QoL). Hence, chronic pain has a significant physical, emotional, cognitive and social impact [15]. Central neuropathic pain, defined as a regional pain caused by a primary lesion or dysfunction in the central nervous system [16] is diagnosed in a significant percentage of MS patients. Chronic pain in MS patients is often neuropathic, but a clear-cut distinction is not easy [17]. For this reason, the recent classifications of pain in MS also include a "mixed pain" category, characterized by both neuropathic and non-neuropathic features $[9,17]$.

Pain and depression are entwined in a complex relationship of situational and physiological connections that are not yet fully understood [18]. Depression has been identified as a predictor of pain in people with MS [19] and chronic pain is linked to depression also in the general population [20]. Pain and depression are strongly associated with MS patients. It has been highlighted that the presence or severity of one condition cross-amplifies the other [21]. Moreover, each condition represents a risk factor for the other. Nevertheless, since patients may have only either one or the other condition, there are likely to be independent and peculiar aspects of both pain and depression [21].

The wide variability reported for the prevalence of pain in MS is attributable to the operational definition of chronic pain used, as well as to the survey methodology. Although several studies already investigated the prevalence of pain in MS and highlighted its association with the Expanded Disability Status Scale (EDSS) [19, 22-24] to the best of our knowledge, no study has investigated its association with the level of disability in the single EDSS Functional Systems. We hypothesize that by using validated tools to assess and characterize the presence of pain in MS patients, we will be able to (a) detect this symptom in a significant percentage of patients and (b) correlate this symptom with disability in one or more EDSS functional systems. The aim of this single-centre cross-sectional study is, therefore, to define the prevalence and characteristics of chronic pain in a population of MS patients using validated tools, and to analyse these data in relation to demographic and clinical features, including disease duration and EDSS with its single functional system scores.

\section{Methods}

\section{Population}

Patients were enrolled consecutively at the MS Center of the Nuovo Ospedale Civile S. Agostino Estense in Modena (Italy) during their routine outpatient visits. Inclusion criteria were as follows: MS diagnosis in accordance with the 2010 McDonald criteria [25], age $>18$ years, ability to give written informed consent and ability to read and write Italian. Patients with a clinical diagnosis of depression were excluded in order to avoid psychological symptom influence and to focus on the unique aspects of pain. All study procedures were conducted according to the Declaration of Helsinki and were approved by the Modena ethics committee (protocol nr. 181/15). All enrolled subjects presented consent capacity and gave written informed consent to the study.

\section{Pain and disability assessment}

Patients underwent a routine neurological examination comprising assessment of disability using EDSS [22] and sensory exam including testing for light touch (brush), pain (pin prick), temperature, vibration (tuning fork) and position sensation.

Neurostatus-certified neurologists (D.F., P.S., A.M.S., F.V.) assessed Kurtzke's Functional Systems and EDSS.

We defined "persistent pain" as frequent or constant pain lasting longer than 3 months (i.e. the typical healing period), as a precise and consistent measure of pain in the MS population. This measure is consistent with recommendations from the IASP and the American College of Rheumatology and was used in a large variety of studies [26, 27].

Prior to written informed consent, patients were asked to fill in the Italian versions of the Brief Pain Inventory (BPI) [28], the Italian Pain Questionnaire (IPQ) [29], the DN 4 questionnaire (DN4) [30, 31], the Neuropathic Pain Symptom Inventory (NPSI) [32] and the Beck's Depression Inventory (BDI) [33]. The DN4 score was used to diagnose neuropathic pain, by considering a cut-off value of 4 , as previously described [30]. The BPI allowed us to evaluate pain severity, pain location on a body chart and the characteristics of the pain and to rate the relief obtained from the pain treatment. We used the NPSI to detect the different symptoms of neuropathic pain. Participants were asked to describe whether they experience bothersome pain and to indicate 1 or more body sites involved. Information on pain treatments was obtained from clinical records and by asking participants to indicate if they were currently using or had ever used any pharmacological pain treatments.

Patients meeting criteria for persistent pain were included in the "Pain Group" (PAIN+). The other patients were included in the "No-PAIN Group" (PAIN-). 


\section{Statistical analyses}

We calculated absolute frequencies and percentages for categorical variables and mean and standard deviation \pm median and interquartile range for continuous variables. We compared demographic and clinical data between groups using the MannWhitney or the Kruskal-Wallis test, as appropriate, for continuous variables and the chi-square test for categorical variables. Associations between variables were calculated using univariable and multivariable logistic regression, which included variables with $p<0.05$ at univariable analysis. Bonferroni correction was used for multiple testing of EDSS FS scores. Otherwise, $p$ values below 0.05 were considered significant. Data was analysed using STATA 11 (StataCorp, Texas, USA).

\section{Results}

\section{Patient characteristics}

Three hundred ninety-seven patients were recruited. Of these, a total of 23 patients were excluded from the analysis because of a mean BDI score higher than 19, to exclude subjects with sub-threshold depression.

Data from 374 patients was analyzed in the study (mean age $46.7 \pm 12.5$ years, 120 males). Patients had different forms of MS: 283 (75.7\%) had relapsing-remitting (RR), while 73 (19.5\%) had primary (PP) or secondary progressive (SP) MS. In particular, 21 (5.7\%) had PPMS and 52 (14\%) had SPMS. Eighteen patients $(4.7 \%)$ had a clinically isolated syndrome (CIS). Two hundred twenty-eight patients were treated with immunomodulatory drugs. Table 1 shows demographic and clinical characteristics of enrolled patients.

\section{Pain characteristics}

Table 2 shows demographic and clinical characteristics of patients with and without persistent pain, whereas Table 3 summarizes the demographic and clinical characteristics of patients with and without neuropathic pain. Table 4 shows the demographic and clinical characteristics of patients with neuropathic pain and with pain other than neuropathic pain. Results of the complete characterization of pain in PAIN+ group are reported in Table 5, including BPI and Italian Pain Questionnaire.

\section{Pain prevalence and localization}

The overall prevalence of chronic pain in our cohort was $52.1 \%$ (195/374). Patients with pain often presented with more than one painful condition [82/195 (42.0\%)]. The pain conditions more frequently experienced by our patients were lower limb pain $(72 / 195 ; 36.9 \%)$, dorsal pain 51/195 (26.1\%),
Table 1 Demographic and clinical features of MS patients. EDSS Expanded Disability Status Scale, $S D$ standard deviation, $M S$ multiple sclerosis, $C I S$ clinically isolated syndrome, $P P$ primary progressive, $S P$ secondary progressive, $M$ male, $F$ female

\begin{tabular}{ll}
\hline Patients & $n=374$ \\
\hline Age (years) (mean \pm SD) & $46.7 \pm 12.5$ \\
Gender & \\
M $(n, \%)$ & $120(32.1)$ \\
F $(n, \%)$ & $254(67.9)$ \\
MS form & \\
CIS $(n, \%)$ & $18(4.7)$ \\
RR $(n, \%)$ & $283(75.6)$ \\
PP $(n, \%)$ & $21(5.7)$ \\
SP $(n, \%)$ & $52(14)$ \\
Disease duration (years) (mean \pm SD) & $13.6 \pm 9.7$ \\
Immunomodulatory/suppressive treatment & \\
Glatiramer acetate $(n, \%)$ & $80(21.4)$ \\
Beta-interferon 1a/1b $(n, \%)$ & $64(17.1)$ \\
Dimethylfumarate $(n, \%)$ & $6(1.6)$ \\
Natalizumab $(n, \%)$ & $42(11.2)$ \\
Fingolimod $(n, \%)$ & $17(4.5)$ \\
Mitoxantrone/azathioprine/teriflunomide $(n, \%)$ & $19(5.1)$ \\
None $(n, \%)$ & $146(39)$ \\
EDSS (mean \pm SD) & $2.5 \pm 2.3$ \\
EDSS (median, interquartile range) & $2.5(1-4)$ \\
\hline
\end{tabular}

low back pain 49/195 (25.1\%) and headache 46/195 (23.6\%). Four patients (1\%) suffered from trigeminal neuralgia.

\section{Comparison between groups}

Patients experiencing persistent pain had a significantly higher level of disability calculated with EDSS than those with no pain ( $2.7 \pm 2.3$ versus $2.3 \pm 2.3)$ (Table 2). EDSS was also higher in patients with neuropathic pain versus all other patients (3.1 \pm 2.1 versus $2.3 \pm 2.3)$ (Table 3 ) and in patients with neuropathic pain versus patients with pain other than neuropathic ( $3.1 \pm 2.1$ versus $2.5 \pm 2.3)$ (Table 4$)$. When we analyzed the single Functional Systems scores (FSSs), the sensory system score, together with the pyramidal and bowel/ bladder FS, was significantly higher in patients with neuropathic pain compared to those without neuropathic pain (Table 3), while, following Bonferroni correction, only the sensory FSs were significantly higher in patients with neuropathic pain compared to patients with pain other than neuropathic (Table 4). No differences in terms of age, MS form, disease duration and gender were found comparing patients with pain and those without pain.

The presence of neuropathic pain was associated at univariate logistic regression with EDSS (OR 1.1; $p=0.007$ ) and sensory (OR 1.6; $p<0,001)$, pyramidal (OR1.2; $p=0.029$ ) and bowel/ 
Table 2 Demographic and clinical characteristics of patients with and without persistent pain. EDSS Expanded Disability Status Scale, FS functional score, $S D$ standard deviation, $M S$ multiple sclerosis, $C I S$ clinically isolated syndrome, $P P$ primary progressive, $S P$ secondary progressive, $M$ male, $F$ female

\begin{tabular}{|c|c|c|c|}
\hline & Patients with pain & Patients without pain & Comparison \\
\hline Patients & $n=195$ & $n=179$ & \\
\hline Age (years) (mean $\pm \mathrm{SD})$ & $47.2 \pm 11.5$ & $46.1 \pm 13.5$ & $p=0.39$ \\
\hline \multicolumn{3}{|l|}{ Gender } & \multirow[t]{3}{*}{$p=0.09$} \\
\hline $\mathrm{M}(n, \%)$ & $55(28.2)$ & $65(36.3)$ & \\
\hline $\mathrm{F}(n, \%)$ & $140(71.8)$ & $114(63.7)$ & \\
\hline \multicolumn{3}{|l|}{ MS form } & \multirow[t]{4}{*}{$p=0.22$} \\
\hline $\mathrm{CIS}+\mathrm{RR}(n, \%)$ & $160(82)$ & $141(78.8)$ & \\
\hline $\mathrm{PP}(n, \%)$ & $7(3.6)$ & $14(7.8)$ & \\
\hline $\mathrm{SP}(n, \%)$ & $28(14.4)$ & $24(13.4)$ & \\
\hline Disease duration (years) (mean $\pm \mathrm{SD}$ ) & $13.8 \pm 10.2$ & $13.4 \pm 9.1$ & $p=0.74$ \\
\hline \multicolumn{3}{|l|}{ Immunomodulatory/suppressive treatment } & \multirow[t]{3}{*}{$p=0.46$} \\
\hline Yes $(n, \%)$ & $120(61.5)$ & $103(57.5)$ & \\
\hline No $(n, \%)$ & $75(38.5)$ & $76(42.5)$ & \\
\hline EDSS (mean \pm SD) & $2.74 \pm 2.28$ & $2.31 \pm 2.30$ & \multirow[t]{2}{*}{$p=0.025$} \\
\hline EDSS (median, interquartile range) & $2(1-4.5)$ & $2(1-3.5)$ & \\
\hline Visual FSS (mean \pm SD) & $0.10 \pm 0.56$ & $0.08 \pm 0.51$ & \multirow[t]{2}{*}{$p=0.503$} \\
\hline Visual FSS (median, interquartile range) & $0(0-0)$ & $0(0-0)$ & \\
\hline Brainstem FSS (mean \pm SD) & $0.37 \pm 0.71$ & $0.31 \pm 0.73$ & \multirow[t]{2}{*}{$p=0.184$} \\
\hline Brainstem FSS (median, interquartile range) & $0(0-1)$ & $0(0-0)$ & \\
\hline Pyramidal FSS $($ mean \pm SD) & $1.61 \pm 1.31$ & $1.41 \pm 1.34$ & \multirow[t]{2}{*}{$p=0.069$} \\
\hline Pyramidal FSS (median, interquartile range) & $1(1-3)$ & $1(0-2)$ & \\
\hline Cerebellar FSS (mean \pm SD) & $0.78 \pm 1.04$ & $0.82 \pm 1.18$ & \multirow[t]{2}{*}{$p=0.899$} \\
\hline Cerebellar FSS (median, interquartile range) & $0(0-2)$ & $0(0-2)$ & \\
\hline Sensory FSS (mean \pm SD) & $0.91 \pm 1.10$ & $0.67 \pm 1.05$ & \multirow[t]{2}{*}{$p=0.016$} \\
\hline Sensory FSS (median, interquartile range) & $0(0-2)$ & $0(0-1)$ & \\
\hline Bowel/bladder FSS (mean \pm SD) & $0.65 \pm 1.13$ & $0.51 \pm 0.99$ & \multirow[t]{2}{*}{$p=0.183$} \\
\hline Bowel/bladder FSS (median, interquartile range) & $0(0-1)$ & $0(0-1)$ & \\
\hline Cerebral FSS (mean \pm SD) & $0.11 \pm 0.47$ & $0.05 \pm 0.36$ & \multirow[t]{2}{*}{$p=0.055$} \\
\hline Cerebral FSS (median, interquartile range) & $0(0-0)$ & $0(0-0)$ & \\
\hline
\end{tabular}

The statistically significant $p$ values are presented in italics

bladder (OR1.3; $p=0.020)$ functional system involvement. At multivariable analysis, only the sensory FS maintained a statistical significance (OR1.7; $p=0.001)$. There was no association between neuropathic pain and age, MS form, sex or disease duration.

\section{Analysis of PAIN group}

When considering the 195 patients experiencing persistent pain, in 89 out of 195 (45.6\% of patients with chronic pain, overall prevalence of $23.7 \%$ ) of them, the pain had neuropathic features. Thirty-eight patients (20.2\%) had continuous pain; 20/195 patients $(10.6 \%)$ had a mean duration of pain attacks of 8-12 h; in $24 / 195$ patients $(12.8 \%)$, the mean duration of the attacks was 4 $7 \mathrm{~h} ; 31 / 195(16.5 \%)$ patients had a mean duration of $1-3 \mathrm{~h}$; in 32/ 195 patients $(17.0 \%)$, pain attacks lasted less than $1 \mathrm{~h}$, whereas 50 patients $(25.6 \%)$ did not specify the duration of pain attacks. One hundred fifty-four patients (78.9\%) experienced pain more than once a week. No significant difference in the prevalence of neuropathic pain was seen when comparing the different types of
MS, nor the different groups of patients divided according to the ongoing disease-modifying treatments. Furthermore, there was no difference in the intensity of pain in different MS types or in patients treated with different disease-modifying drugs.

Pain severity (as per BPI severity score) in patients with chronic pain was low (1-4) in $116(59 \%)$, moderate (5-6) in $52(27 \%)$ and severe $(>6)$ in $27(14 \%)$ patients. In patients with neuropathic pain, there was a lower percentage of patients with low-intensity pain (46 patients, $52 \%$ ) and a higher percentage of patients with severe pain (18 patients, $20 \%$ ). The BPI severity score was significantly higher in patients with neuropathic pain as opposed to patients with nonneuropathic pain $(4.6 \pm 2.3$ versus $3.6 \pm 1.9, p=0.005)$.

\section{Pain treatment}

A total of 57 patients (15.2\%) were on long-lasting treatment with drugs commonly prescribed for chronic pain. Most frequently prescribed drugs were gabapentin (19 patients $33.3 \%$ of all 
Table 3 Demographic and clinical characteristics of patients with and without neuropathic pain. EDSS Expanded Disability Status Scale, $F S$ functional score, $S D$ standard deviation, $M S$ multiple sclerosis, $C I S$ clinically isolated syndrome, $P P$ primary progressive, $S P$ secondary progressive, $M$ male, $F$ female

\begin{tabular}{|c|c|c|c|}
\hline & Patients with neuropathic pain & Patients without neuropathic pain & Comparison \\
\hline Patients & $n=89$ & $n=285$ & \\
\hline Age (years) (mean $\pm \mathrm{SD})$ & $47.1 \pm 10.9$ & $46.6 \pm 12.9$ & $p=0.73$ \\
\hline \multicolumn{3}{|l|}{ Gender } & \multirow[t]{3}{*}{$p=0.89$} \\
\hline $\mathrm{M}(n, \%)$ & $29(32.6)$ & $91(31.9)$ & \\
\hline $\mathrm{F}(n, \%)$ & $60(67.4)$ & $194(68.1)$ & \\
\hline \multicolumn{3}{|l|}{ MS form } & \multirow[t]{4}{*}{$p=0.5$} \\
\hline $\mathrm{CIS}+\mathrm{RR}(n, \%)$ & $75(84.3)$ & $226(79.3)$ & \\
\hline $\mathrm{PP}(n, \%)$ & $3(3.4)$ & $18(6.3)$ & \\
\hline $\mathrm{SP}(n, \%)$ & $11(12.3)$ & $41(14.4)$ & \\
\hline Disease duration (years) (mean $\pm \mathrm{SD}$ ) & $14.1 \pm 10.7$ & $13.4 \pm 9.4$ & $p=0.53$ \\
\hline \multicolumn{3}{|l|}{ Immunomodulatory/suppressive treatment } & \multirow[t]{3}{*}{$p=0.70$} \\
\hline Yes $(n, \%)$ & $59(66.3)$ & $174(61.1)$ & \\
\hline No $(n, \%)$ & $30(33.7)$ & $101(39.9)$ & \\
\hline EDSS (mean \pm SD) & $3.12 \pm 2.15$ & $2.35 \pm 2.32$ & \multirow[t]{2}{*}{$p<0.001$} \\
\hline EDSS (median, interquartile range) & $2.5(1.5-4.5)$ & $1.5(1-3.5)$ & \\
\hline Visual FSS (mean \pm SD) & $0.16 \pm 0.74$ & $0.07 \pm 0.45$ & \multirow[t]{2}{*}{$p=0.207$} \\
\hline Visual FSS (median, interquartile range) & $0(0-0)$ & $0(0-0)$ & \\
\hline Brainstem FSS $($ mean \pm SD) & $0.42 \pm 0.75$ & $0.32 \pm 0.71$ & \multirow[t]{2}{*}{$p=0.164$} \\
\hline Brainstem FSS (median, interquartile range) & $0(0-1)$ & $0(0-0)$ & \\
\hline Pyramidal FSS (mean \pm SD) & $1.79 \pm 1.22$ & $1.43 \pm 1.35$ & \multirow[t]{2}{*}{$p=0.005$} \\
\hline Pyramidal FSS (median, interquartile range) & $2(1-3)$ & $1(0-2)$ & \\
\hline Cerebellar FSS $($ mean \pm SD) & $0.91 \pm 0.97$ & $0.76 \pm 1.11$ & \multirow[t]{2}{*}{$p=0.115$} \\
\hline Cerebellar FSS (median, interquartile range) & $1(0-2)$ & $0(0-1)$ & \\
\hline Sensory FSS (mean \pm SD) & $1.25 \pm 1.15$ & $0.66 \pm 1.02$ & \multirow[t]{2}{*}{$p<0.001$} \\
\hline Sensory FSS (median, interquartile range) & $1(0-2)$ & $0(0-1)$ & \\
\hline Bowel/bladder FSS (mean \pm SD) & $0.82 \pm 1.22$ & $0.51 \pm 0.99$ & \multirow[t]{2}{*}{$p=0.005$} \\
\hline Bowel/bladder FSS (median, interquartile range) & $0(0-1)$ & $0(0-1)$ & \\
\hline Cerebral FSS (mean \pm SD) & $0.08 \pm 0.4$ & $0.08 \pm 0.42$ & \multirow[t]{2}{*}{$p=0.784$} \\
\hline Cerebral FSS (median, interquartile range) & $0(0-0)$ & $0(0-0)$ & \\
\hline
\end{tabular}

The statistically significant $p$ values are presented in italics

treated patients), pregabalin (16 patients; $28 \%)$, duloxetine (12 patients; $21 \%$ ) and amitriptyline (9 patients; $16 \%$ ). A further 11 patients $(5.6 \%)$ had been prescribed a cannabinoid-based oral spray for spasticity. Twenty patients $(10.2 \%)$ were on more than one drug for the treatment of pain. Mean efficacy score in the total sample was $40.0 \pm 30.0$. Symptomatic treatment with nonsteroidal anti-inflammatory drugs (NSAIDs) was routinely used by $80 / 195$ patients $(42.1 \%)$, whereas $6 / 195(3.1 \%)$ patients used opioid drugs. Of all patients with chronic pain, 47 patients (24\%) were treated with either gabapentin, pregabalin, duloxetine, amitriptyline or carbamazepine, and of all patients with neuropathic pain 29 patients $(33 \%)$ were treated with at least one of the abovementioned drugs.

\section{Discussion}

In this study, we assessed the prevalence of persistent pain in a MS population followed up at a tertiary centre. The population included patients at all disease stages: from disease onset to long-standing progressive course. Patient disability was characterized by recording all scores in the single EDSS functional systems. Our results revealed that more than half of MS patients fulfilled criteria for the diagnosis of persistent pain, confirming the high prevalence of this symptom in MS. We also found that neuropathic pain was the most prevalent type of chronic pain in MS patients, with an overall prevalence of $23.7 \%$ of all the studied patients, not very dissimilar to the pooled, overall $28.5 \%$ prevalence of neuropathic pain in MS, reported in a meta-analysis (Foley et al. 2013).

Several studies have already investigated the prevalence of pain in MS patients, with very heterogeneous results. This can be due to methodological differences [8,9], especially in the classifications and definitions of the symptoms, the methods used to measure it and the inclusion criteria of the studied populations. The majority of the previous studies, for example, did not define "persistent pain", as a frequent or constant pain lasting longer than 3 months and this may be a reason to 
Table 4 Demographic and clinical characteristics of patients with neuropathic pain and with pain other than neuropathic pain. EDSS Expanded Disability Status Scale, $F S$ functional score, $S D$ standard deviation, $M S$ multiple sclerosis, $C I S$ clinically isolated syndrome, $P P$ primary progressive, $S P$ secondary progressive, $M$ male, $F$ female

\begin{tabular}{|c|c|c|c|}
\hline & $\begin{array}{l}\text { Patients with } \\
\text { neuropathic pain }\end{array}$ & $\begin{array}{l}\text { Patients with pain other } \\
\text { than neuropathic pain }\end{array}$ & Comparison \\
\hline Patients & $n=89 *$ & $n=103^{*}$ & \\
\hline Age (years) (mean $\pm \mathrm{SD})$ & $47.1 \pm 10.9$ & $46.6 \pm 12.9$ & $p=0.86$ \\
\hline $\begin{array}{l}\text { Gender } \\
\mathrm{M}(n, \%)\end{array}$ & $29(32.6)$ & $25(24.3)$ & $p=0.26$ \\
\hline $\mathrm{F}(n, \%)$ & $60(67.4)$ & $78(75.7)$ & \\
\hline $\begin{array}{l}\text { MS form } \\
\text { CIS + RR }(n, \%)\end{array}$ & $75(84.3)$ & $82(79.6)$ & $p=0.75$ \\
\hline $\mathrm{PP}(n, \%)$ & $3(3.4)$ & $4(3.9)$ & \\
\hline $\mathrm{SP}(n, \%)$ & $11(12.4)$ & $17(16.5)$ & \\
\hline Disease duration (years) (mean $\pm \mathrm{SD}$ ) & $14.1 \pm 10.7$ & $13.5 \pm 9.9$ & $p=0.68$ \\
\hline $\begin{array}{l}\text { Immunomodulatory/suppressive treatment } \\
\text { Yes }(n, \%)\end{array}$ & $59(66.3)$ & $61(59.2)$ & $p=0.37$ \\
\hline No $(n, \%)$ & $30(33.7)$ & $42(40.1)$ & \\
\hline $\begin{array}{l}\text { EDSS (mean } \pm \text { SD) } \\
\text { EDSS (median, interquartile range) }\end{array}$ & $\begin{array}{l}3.12 \pm 2.15 \\
2.5(1.5-4.5)\end{array}$ & $\begin{array}{l}2.48 \pm 2.35 \\
1.5(1-3.5)\end{array}$ & $p=0.007$ \\
\hline $\begin{array}{l}\text { Visual FSS (mean } \pm \text { SD) } \\
\text { Visual FSS (median, interquartile range) }\end{array}$ & $\begin{array}{l}0.16 \pm 0.74 \\
0(0-0)\end{array}$ & $\begin{array}{l}0.06 \pm 0.37 \\
0(0-0)\end{array}$ & $p=0.342$ \\
\hline $\begin{array}{l}\text { Brainstem FSS (mean } \pm \text { SD) } \\
\text { Brainstem FSS (median, interquartile range) }\end{array}$ & $\begin{array}{l}0.42 \pm 0.75 \\
0(0-1)\end{array}$ & $\begin{array}{l}0.34 \pm 0.68 \\
0(0-1)\end{array}$ & $p=0.502$ \\
\hline $\begin{array}{l}\text { Pyramidal FSS (mean } \pm \text { SD) } \\
\text { Pyramidal FSS (median, interquartile range) }\end{array}$ & $\begin{array}{l}1.79 \pm 1.22 \\
2(1-3)\end{array}$ & $\begin{array}{l}1.50 \pm 1.38 \\
1(0-2)\end{array}$ & $p=0.053$ \\
\hline $\begin{array}{l}\text { Cerebellar FSS (mean } \pm \text { SD) } \\
\text { Cerebellar FSS (median, interquartile range) }\end{array}$ & $\begin{array}{l}0.91 \pm 0.97 \\
1(0-2)\end{array}$ & $\begin{array}{l}0.69 \pm 1.01 \\
0(0-1)\end{array}$ & $p=0.100$ \\
\hline $\begin{array}{l}\text { Sensory FSS (mean } \pm \text { SD) } \\
\text { Sensory FSS (median, interquartile range) }\end{array}$ & $\begin{array}{l}1.25 \pm 1.15 \\
1(0-2)\end{array}$ & $\begin{array}{l}0.65 \pm 0.99 \\
0(0-1)\end{array}$ & $p<0.001$ \\
\hline $\begin{array}{l}\text { Bowel/bladder FSS (mean } \pm \text { SD) } \\
\text { Bowel/bladder FSS (median, interquartile range) }\end{array}$ & $\begin{array}{l}0.82 \pm 1.22 \\
0(0-1)\end{array}$ & $\begin{array}{l}0.52 \pm 1.04 \\
0(0-1)\end{array}$ & $p=0.023$ \\
\hline $\begin{array}{l}\text { Cerebral FSS (mean } \pm \text { SD) } \\
\text { Cerebral FSS (median, interquartile range) }\end{array}$ & $\begin{array}{l}0.08 \pm 0.4 \\
0(0-0)\end{array}$ & $\begin{array}{l}0.15 \pm 0.53 \\
0(0-0)\end{array}$ & $p=0.174$ \\
\hline
\end{tabular}

The statistically significant $p$ values are presented in italics

*3 patients were excluded because of incomplete compilation of DN4 questionnaire

explain the high inconsistency of the different studies. In addition, a number of different and often non-validated screening tools for pain have been previously used to assess pain in MS, thus leading to the inconsistency of the findings reported in the literature. The present study used specific validated tools to characterize the type of persistent pain. In fact, we used two validated tools, the DN 4 questionnaire (DN4) [30, 31 ] and the NPSI [32], that discriminate and quantify different and clinical dimensions of neuropathic pain. The correlation of pain in MS patients with disease duration and age is also very inconsistent among previous reports. Some older studies found an association of pain with disease duration and age $[23,34]$; however, this was not confirmed by following researches [2, 24, 35-38]. Our study lends support to these newer studies, suggesting that in MS, pain is neither associated with age nor with disease duration. A similar inconsistency among previous studies also exists for the gender-related differences. Pain was found to be more prevalent in female MS patients [34, 39], but this has not been confirmed in all studies [23, 36], being the significant difference possibly due to the fact that women are generally more likely to experience a variety of recurrent pain syndromes [40], or to the expected higher prevalence of tension-type headache and migraine in female patients [4]. In our study, the pain symptoms were independent of gender, confirming that this may not be a key factor for the development of pain in MS. In the present study, the level of clinical disability as evaluated with EDSS was significantly higher in MS patients experiencing pain, and in MS patients experiencing neuropathic pain as compared to those experiencing non-neuropathic pain. This observation is in line with those reported in the majority [9, 19, 24, 41], but not all $[23,36]$ published studies, therefore suggesting that clinical disability represents the key factor for the development of pain. The exclusion of subjects with a clinical 
Table 5 Brief Pain Inventory and Italian Pain Questionnaire scores of patients with persistent or chronic pain. $S D$ standard deviation

\begin{tabular}{lc}
\hline Patients with persistent or chronic pain & $n=195$ \\
\hline Brief Pain Inventory & \\
Pain Severity Score (0-10) (mean \pm SD) & $4.06 \pm 2.16$ \\
Pain Interference Score (0-10) (mean \pm SD) & $3.79 \pm 2.74$ \\
Italian Pain Questionnaire - number of words chosen (NWC) \\
Total-NWC (0-42) (mean \pm SD) & $8.76 \pm 5.55$ \\
Sensory-NWC (0-19) (mean \pm SD) & $4.66 \pm 2.66$ \\
Affective-NWC (0-9) (mean \pm SD) & $2.09 \pm 1.65$ \\
Evaluative-NWC (0-8) (mean \pm SD) & $1.94 \pm 1.21$ \\
Miscellaneous-NWC (0-6) (mean \pm SD) & $1.24 \pm 1.15$ \\
Present pain intensity (PPI) (0-5) (mean \pm SD) & $1.64 \pm 1.10$ \\
\hline
\end{tabular}

diagnosis of depression, as well as of those with pathological scores at the BDI, eliminates the possible influence of mood problems on the observed association between pain and disability [42]. Despite the association between disease duration and disability, and between disability and pain, the role of longer disease duration on pain in MS is not well characterized. In this study, for example, we did not observe any association between pain prevalence and disease length, while a recent study [24] on patients with "early" MS found a very low prevalence of pain, and Stenager and colleagues [23] reported a significantly increased prevalence of chronic pain problems over a 5-year period. Therefore, future studies need to clarify these apparently contradictory data and to evaluate why, even though pain is correlated with disability and its prevalence increases with time, there is no clear association with disease duration. It is possible that patients with pain are more likely to deteriorate clinically. In fact, other authors reported, in large populations of chronic pain patients, no differences in terms of absolute severity, but statistical differences only in the pattern of pain quality and in its spatial characteristics [43]. It is conceivable that, in MS patients, as opposed to other chronic pain patients, mechanisms of central pain processing contribute to neuropathic pain.

In relation to treatment, it is remarkable that two thirds of patients with neuropathic pain were untreated: only 29 patients - approximately one third of patients - with neuropathic pain were on a specific long-lasting treatment for pain. Since a total of 57 patients were treated with drugs indicated for the treatment of neuropathic pain, this finding indicates that some patients were probably prescribed these drugs for other indications such as depression/insomnia/fatigue in the case of amitriptyline/duloxetine or for non-painful paraesthesias in the case of gabapentin/pregabalin.

Proper randomized controlled trials for pain management in MS are still lacking, mainly due to the difficulty of performing placebo-controlled studies because of ethical considerations [44]. It should be noted that antiepileptic medications (gabapentin and pregabalin) were the most commonly prescribed drugs in our cohort. Probably, this is due to the single-centre preferences and guidelines; nevertheless, antiepileptic medications, together with tricyclic antidepressants, baclofen and cannabinoids are well known to be the most commonly used analgesic drugs in MS [44].

This study has strengths and limitations. First, we believe that the exclusion of moderately and severely depressed patients from the analysis may have limited the bias of depression, increasing the reliability of our results in relation to the unique and peculiar clinical aspects of pain. The main limitation due to the exclusion of moderately and severely depressed patients is that we could have excluded patients with higher pain intensity that are frequently depressed [21]. In fact, patients with higher pain tend to experience also worse depressive symptomatology. This aspect has been related to the partial overlap of both central nociceptive and affective pathways that also share underlying neurotransmitters, mainly norepinephrine and serotonin. Significantly, the treatment of both conditions may be the same and treating one condition may benefit the other [21]. Nevertheless, we believe that the inclusion of depressed patients or the failure to assess patients' mood in previous studies may represent another reason to explain the enormous variability of the reported prevalence of pain in MS. As for the study limits, firstly, our population may not be fully representative of the MS population, since patients with severe disability may, at some stage, stop attending follow-up visits at outpatient tertiary centres due to logistic difficulties. Another important limitation of the study is the lack of the tools used to identify spasticity-related pain that is an important type of pain in the MS population. Finally, we only evaluated the prevalence and the features of pain based on validated questionnaires and clinical assessments, without analysing the MRI scans of these patients. This might have improved the characterization of our cohort.

\section{Conclusion}

Taken together, our results suggest that clinical disability is higher in MS patients with chronic pain and, in particular, in those with neuropathic pain. On the contrary, chronic pain is not associated with age, disease duration or with gender. The association between sensory FS involvement and neuropathic pain suggests that clinical disability in the sensory system is important for neuropathic pain occurrence in MS patients.

Given the high prevalence of persistent pain and, in particular, of neuropathic pain in MS patients, and the relatively low percentage of adequately treated patients, the present study supports the routine assessment of neuropathic pain in MS patients, especially those with involvement of the sensory functional system, in order to avoid underdiagnosing and undertreating a potentially disabling condition. 
Compliance with ethical standards All study procedures were conducted according to the Declaration of Helsinki and were approved by the Modena ethics committee (protocol nr. 181/15). All enrolled subjects presented consent capacity and gave written informed consent to the study.

Conflict of interest DP received the "Premio Anna Paola Batocchi" 2nd edition from Fondazione Cesare Serono. DF declares that there is no conflict of interest. FM declares that there is no conflict of interest. GD declares that there is no conflict of interest. AMS declares that there is no conflict of interest. FV declares that there is no conflict of interest. PS declares that there is no conflict of interest. GP declares that there is no conflict of interest. VN declares that there is no conflict of interest. MP declares that there is no conflict of interest. MM declares that there is no conflict of interest. CV declares that there is no conflict of interest.

\section{References}

1. Clifford DB, Trotter JL (1984) Pain in multiple sclerosis. Arch Neurol 41(7):1270-1272. https://doi.org/10.1212/WNL.39.7.1001

2. Kalia LV, O'Connor PW (2005) Severity of chronic pain and its relationship to quality of life in multiple sclerosis. Mult Scler 11(3): 322-327. https://doi.org/10.1191/1352458505ms1168oa

3. Khan F, Pallant J (2007) Chronic pain in multiple sclerosis: prevalence, characteristics, and impact on quality of life in an Australian community cohort. J Pain 8(8):614-623. https://doi.org/10.1016/j. jpain.2007.03.005

4. Martinelli Boneschi F, Colombo B, Annovazzi P, Martinelli V, Bernasconi L, Solaro C, Comi G (2008) Lifetime and actual prevalence of pain and headache in multiple sclerosis. Mult Scler 14(4): 514-521. https://doi.org/10.1177/1352458507085551

5. Moulin DE (1989) Pain in multiple sclerosis. Neurol Clin 7(2):321-331

6. Solaro C, Trabucco E, Messmer Uccelli M (2013) Pain and multiple sclerosis: pathophysiology and treatment. Curr Neurol Neurosci Rep 13(1):320. https://doi.org/10.1007/s11910-012-0320-5

7. Hirsh AT, Turner AP, Ehde DM, Haselkorn JK (2009) Prevalence and impact of pain in multiple sclerosis: physical and psychologic contributors. Arch Phys Med Rehabil 90(4):646-651. https://doi. org/10.1016/j.apmr.2008.10.019

8. Foley PL, Vesterinen HM, Laird BJ, Sena ES, Colvin LA, Chandran S, MacLeod MR, Fallon MT (2013) Prevalence and natural history of pain in adults with multiple sclerosis: systematic review and meta-analysis. Pain 154(5):632-642. https://doi.org/10. 1016/j.pain.2012.12.002

9. O'Connor AB, Schwid SR, Herrmann DN, Markman JD, Dworkin RH (2008) Pain associated with multiple sclerosis: systematic review and proposed classification. Pain 137(1):96-111. https://doi. org/10.1016/j.pain.2007.08.024

10. Campbell JN, Meyer RA (2006) Mechanisms of neuropathic pain. Neuron 52(1):77-92. https://doi.org/10.1016/j.neuron.2006.09.021

11. Scholz J, Woolf CJ (2002) Can we conquer pain? Nat Neurosci 5(Supp):1062-1067. https://doi.org/10.1038/nn942

12. Treede RD, Jensen TS, Campbell JN, Cruccu G, Dostrovsky JO, Griffin JW, Hansson P, Hughes R, Nurmikko T, Serra J (2008) Neuropathic pain: redefinition and a grading system for clinical and research purposes. Neurology 70(18):1630-1635. https://doi. org/10.1212/01.wnl.0000282763.29778.59

13. Turk DC, Okifuji A (2001) Pain terms and taxonomies. In: Loeser D, Butler SH, Chapman JJ, Turk DC (eds) Bonica's Manag. Pain, 3rd edn. Lippincott Williams \& Wilkins, Philadelphia, pp 18-25

14. Main CJ, Spanswick CC (2000) Pain management: an interdisciplinary approach. Churchill Livingstone, London
15. Breivik H, Collett B, Ventafridda V, Cohen R, Gallacher D (2006) Survey of chronic pain in Europe: prevalence, impact on daily life, and treatment. Eur J Pain 10(4):287-333. https://doi.org/10.1016/j. ejpain.2005.06.009

16. Merskey H, Bogduk N (1994) Classification of chronic pain. IASP Pain Terminol 57(3):425-429. https://doi.org/10.1002/ana.20394

17. Truini A, Barbanti P, Pozzilli C, Cruccu G (2013) A mechanismbased classification of pain in multiple sclerosis. J Neurol 260(2): 351-367. https://doi.org/10.1007/s00415-012-6579-2

18. Chopra K, Arora V (2014) An intricate relationship between pain and depression: clinical correlates, coactivation factors and therapeutic targets. Expert Opin Ther Targets 18(2):159-176. https://doi. org $/ 10.1517 / 14728222.2014 .855720$

19. Hadjimichael O, Kerns RD, Rizzo MA, Cutter G, Vollmer T (2007) Persistent pain and uncomfortable sensations in persons with multiple sclerosis. Pain 127(1):35-41. https://doi.org/10.1016/j.pain. 2006.07.015

20. Fishbain DA, Cutler R, Rosomoff HL, Rosomoff RS (1997) Chronic pain-associated depression: antecedent or consequence of chronic pain? A review. Clin J Pain 13(2):116-137. https://doi.org/ 10.1097/00002508-199706000-00006

21. Alschuler KN, Ehde DM, Jensen MP (2013) Co-occurring depression and pain in multiple sclerosis. Phys Med Rehabil Clin N Am 24(4):703-715. https://doi.org/10.1016/j.pmr.2013.06.001

22. Kurtzke JF (1983) Rating neurologic impairment in multiple sclerosis: an expanded disability status scale (EDSS). Neurology 33(11):1444-1452. https://doi.org/10.1212/WNL.33.11.1444

23. Stenager E, Knudsen L, Jensen K (1995) Acute and chronic pain syndromes in multiple sclerosis. A 5-year follow-up study. Ital J Neurol Sci 16(8):629-632. https://doi.org/10.1007/BF02230913

24. Heitmann H, Biberacher V, Tiemann L, Buck D, Loleit V, Selter RC, Knier B, Tölle TR, Mühlau M, Berthele A, Hemmer B, Ploner M (2015) Prevalence of neuropathic pain in early multiple sclerosis. Mult Scler J 22(9):8-11. https://doi.org/10.1177/ 1352458515613643

25. Polman CH, Reingold SC, Banwell B, Clanet M, Cohen JA, Filippi M, Fujihara K, Havrdova E, Hutchinson M, Kappos L, Lublin FD, Montalban X, O'Connor P, Sandberg-Wollheim M, Thompson AJ, Waubant E, Weinshenker B, Wolinsky JS (2011) Diagnostic criteria for multiple sclerosis: 2010 revisions to the McDonald criteria. Ann Neurol 69(2):292-302. https://doi.org/10.1002/ana.22366

26. Ohayon MM, Stingl JC (2012) Prevalence and comorbidity of chronic pain in the German general population. J Psychiatr Res 46(4):444 450. https://doi.org/10.1016/j.jpsychires.2012.01.001

27. Blyth FM, March LM, Brnabic AJM, Jorm LR, Williamson M, Cousins MJ (2001) Chronic pain in Australia: a prevalence study. Pain 89(2): 127-134. https://doi.org/10.1016/S0304-3959(00)00355-9

28. Caraceni A, Mendoza TR, Mencaglia E, Baratella C, Edwards K, Forjaz MJ, Martini C, Serlin RC, de Conno F, Cleeland CS (1996) A validation study of an Italian version of the Brief Pain Inventory (Breve Questionario per la Valutazione del Dolore). Pain 65(1):8792. https://doi.org/10.1016/0304-3959(95)00156-5

29. De Benedittis G, Massei R, Nobili R, Pieri A (1988) The Italian pain questionnaire. Pain 33(1):53-62. https://doi.org/10.1016/ 0304-3959(88)90203-5

30. Bouhassira D, Attal N, Fermanian J, Alchaar H, Gautron M, Masquelier E, Rostaing S, Lanteri-Minet M, Collin E, Grisart J, Boureau F (2004) Development and validation of the Neuropathic Pain Symptom Inventory. Pain 108(3):248-257. https://doi.org/10. 1016/j.pain.2003.12.024

31. Spallone V, Morganti R, D'Amato C, Greco C, Cacciotti L, Marfia GA (2012) Validation of DN4 as a screening tool for neuropathic pain in painful diabetic polyneuropathy. Diabet Med 29(5):578 585. https://doi.org/10.1111/j.1464-5491.2011.03500.x

32. Padua L, Briani C, Jann S, Nobile-Orazio E, Pazzaglia C, Morini A, Mondelli M, Ciaramitaro P, Cavaletti G, Cocito D, Fazio R, Santoro 
L, Galeotti F, Carpo M, Plasmati R, Benedetti L, Schenone A, Marchettini P, Cruccu G (2009) Validation of the Italian version of the Neuropathic Pain Symptom Inventory in peripheral nervous system diseases. Neurol Sci 30(2):99-106. https://doi.org/10.1007/ s10072-009-0025-y

33. Beck AT, Ward CH, Mendelson M et al (1961) An inventory for measuring depression. Arch Gen Psychiatry 4(6):561-571. https:// doi.org/10.1001/archpsyc.1961.01710120031004

34. Moulin DE, Foley KM, Ebers GC (1988) Pain syndromes in multiple sclerosis. Neurology 38(12):1830-1834. https://doi.org/10. 1212/WNL.38.12.1830

35. Archibald CJ, McGrath PJ, Ritvo PG, Fisk JD, Bhan V, Maxner CE, Murray TJ (1994) Pain prevalence, severity and impact in a clinic sample of multiple sclerosis patients. Pain 58(1):89-93. https://doi. org/10.1016/0304-3959(94)90188-0

36. Beiske AG, Pedersen ED, Czujko B, Myhr K-MM (2004) Pain and sensory complaints in multiple sclerosis. Eur J Neurol 11(7):479482. https://doi.org/10.1111/j.1468-1331.2004.00815.x

37. Grasso MG, Clemenzi A, Tonini A, Pace L, Casillo P, Cuccaro A, Pompa A, Troisi E (2008) Pain in multiple sclerosis: a clinical and instrumental approach. Mult Scler 14(4):506-513. https://doi.org/ $10.1177 / 1352458507085553$
38. Rae-Grant ADD, Eckert NJJ, Bartz S, Reed JF (1999) Sensory symptoms of multiple sclerosis: a hidden reservoir of morbidity. Mult Scler 5(3):179-183. https://doi.org/10.1191/ 135245899678846032

39. Warnell P (1991) The pain experience of a multiple sclerosis population: a descriptive study. Axone 13(1):26-28

40. Unruh AM Gender variations in clinical pain experience. Pain 65: $123-167$

41. Truini A, Galeotti F, La Cesa S, di Rezze S, Biasiotta A, di Stefano G, Tinelli E, Millefiorini E, Gatti A, Cruccu G (2012) Mechanisms of pain in multiple sclerosis: a combined clinical and neurophysiological study. Pain 153(10):2048-2054. https://doi.org/10.1016/j. pain.2012.05.024

42. Holmes A, Christelis N, Arnold C (2013) Depression and chronic pain. Med J Aust 199(6 Suppl):S17-S20

43. Dworkin RH, Jensen MP, Gammaitoni AR, Olaleye DO, Galer BS (2007) Symptom profiles differ in patients with neuropathic versus non-neuropathic pain. J Pain 8(2):118-126. https://doi.org/10.1016/ j.jpain.2006.06.005

44. Solaro C, Messmer Uccelli M (2011) Management of pain in multiple sclerosis: a pharmacological approach. Nat Rev Neurol 7(9): 519-527. https://doi.org/10.1038/nrneurol.2011.120 